
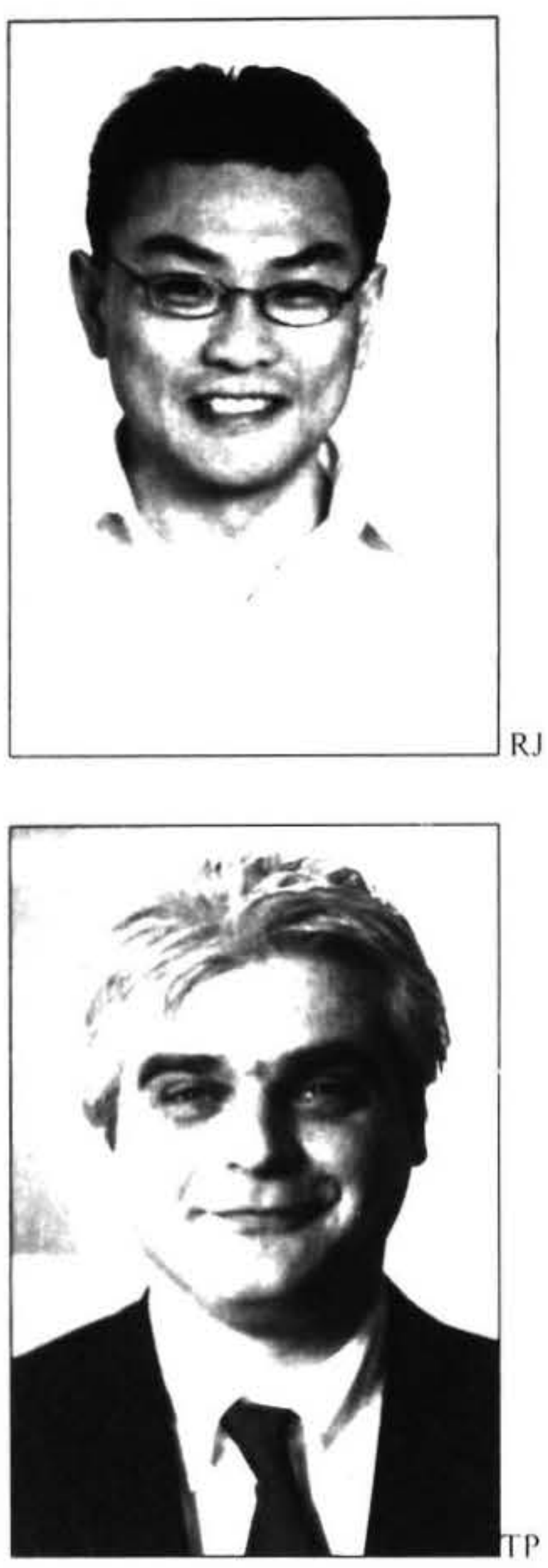

PERSON LEVEL STATISTICS USING LINKED EMPLOYEREMPLOYEE DATA

\section{Rodney Jer}

Work, Knowledge and Skills, Statistics New Zealand, Wellington

\section{Ian McGregor}

Work, Knowledge and Skills, Statistics New Zealand, Wellington

\section{Tas Papadopoulos}

Work, Knowledge and Skills, Statistics New Zealand. Wellington

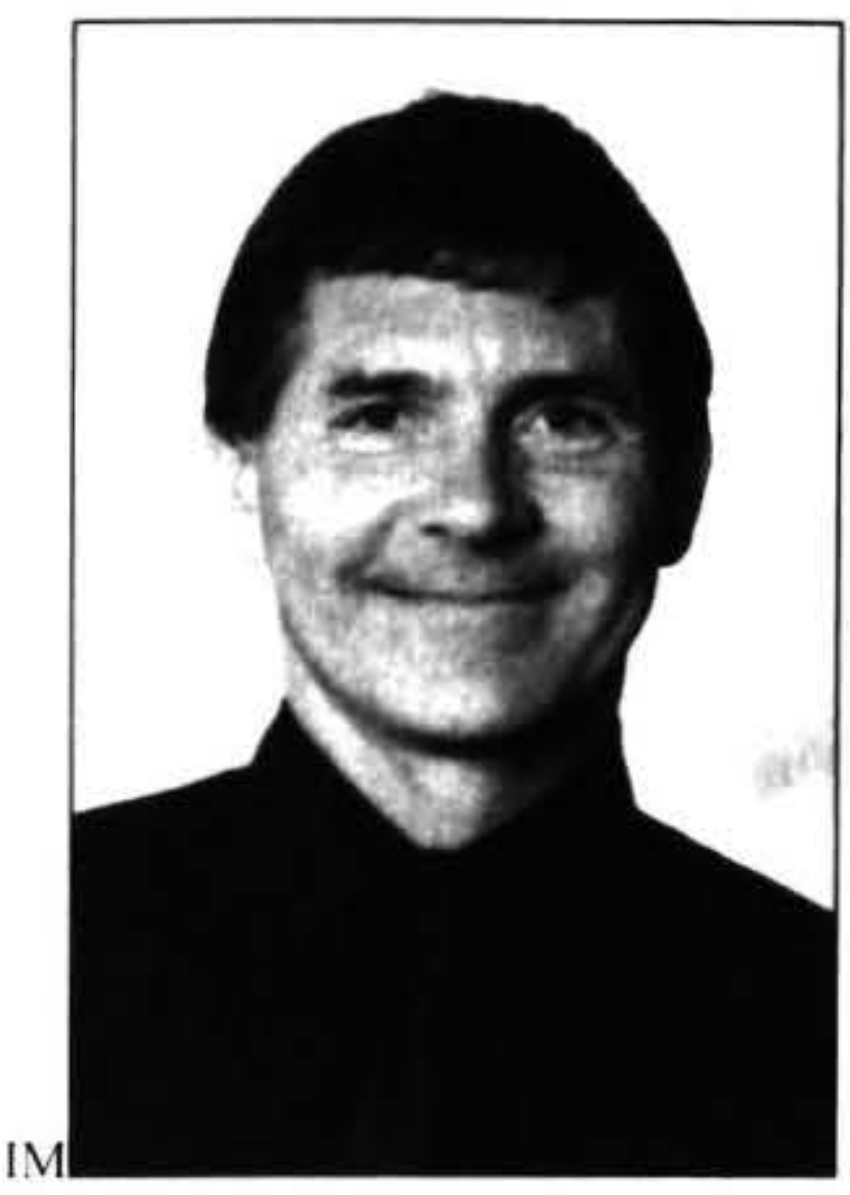

\begin{abstract}
New statistical measures were puhlished in a report by. Statistics New Zealand on 24 October 2006 from the Linked Emplorer-Emploree Dataset (LEED). LEED uses longitudinal information from existing taxation and Statistics NZ source's to provide a range of information on the drnamics of the New Zealand labour market. New statistics have been produced for the first time on income transitions, joh tenure, multiple joh holding and the self-emploved. The use of administrative data allows Statistics. New Zealand to produce new statistics ar level of regional and industry detail not arailahle from existing sources. Detailed statistics from the 2000) to 2005 tax years are arailable on the Statistics New Zealund weh-site. The stutistics are mostly person-level statistics for the period to the end of the 2005 tax year.
\end{abstract}

This paper provides highlights from this report. covering three areas: earnings transitions, multiple job holding as well as new informution on self-emplorment.

LEED can produce these outpuss across time and three other dimensions, age, sex and regional council area. Not all of this information is provided in the amnual release, hut is arailahle. fiee of charge, on Statistics New Zealand's web hased Tahle Builder product.

\section{Introduction}

Statistics produced from the Linked Employer-Employee Data (LEED) measure labour market dynamics, providing an insight into the operation of New Zealand's labour market. These job-level statistics are produced quarterly.

New statistical measures were published in a report by Statistics New Zealand on 24 October 2006 from the Linked Employer-Employee Dataset (LEED). They use LEED's longitudinal nature to present new statistics on income transitions, job tenure. multiple job holding and the self-employed, which fill gaps in the existing statistical framework. The statistics are primarily personlevel statistics for the period to the year ended March 2005.

This paper highlights three areas of interest - selfemployment, earnings transitions and multiple job holding. The full report is available at www.stats.govt.nz/leed

Note that LEED can produce most statistics across time. age, sex and regional council area. All of this information cannot be provided in this paper, but is available, free of 
charge, on Statistics New Zealand's web-based Table Builder product'.

\section{Self-Employment}

Annual statistics about self-employed people are available from the Linked Employer-Employee Data (LEED). Self-employed data is available from the 2000 tax year and relates to persons receiving self-employment income from which tax is deducted.

Figure 1: Distribution of self-employment persons by industry, year ended March 2005.

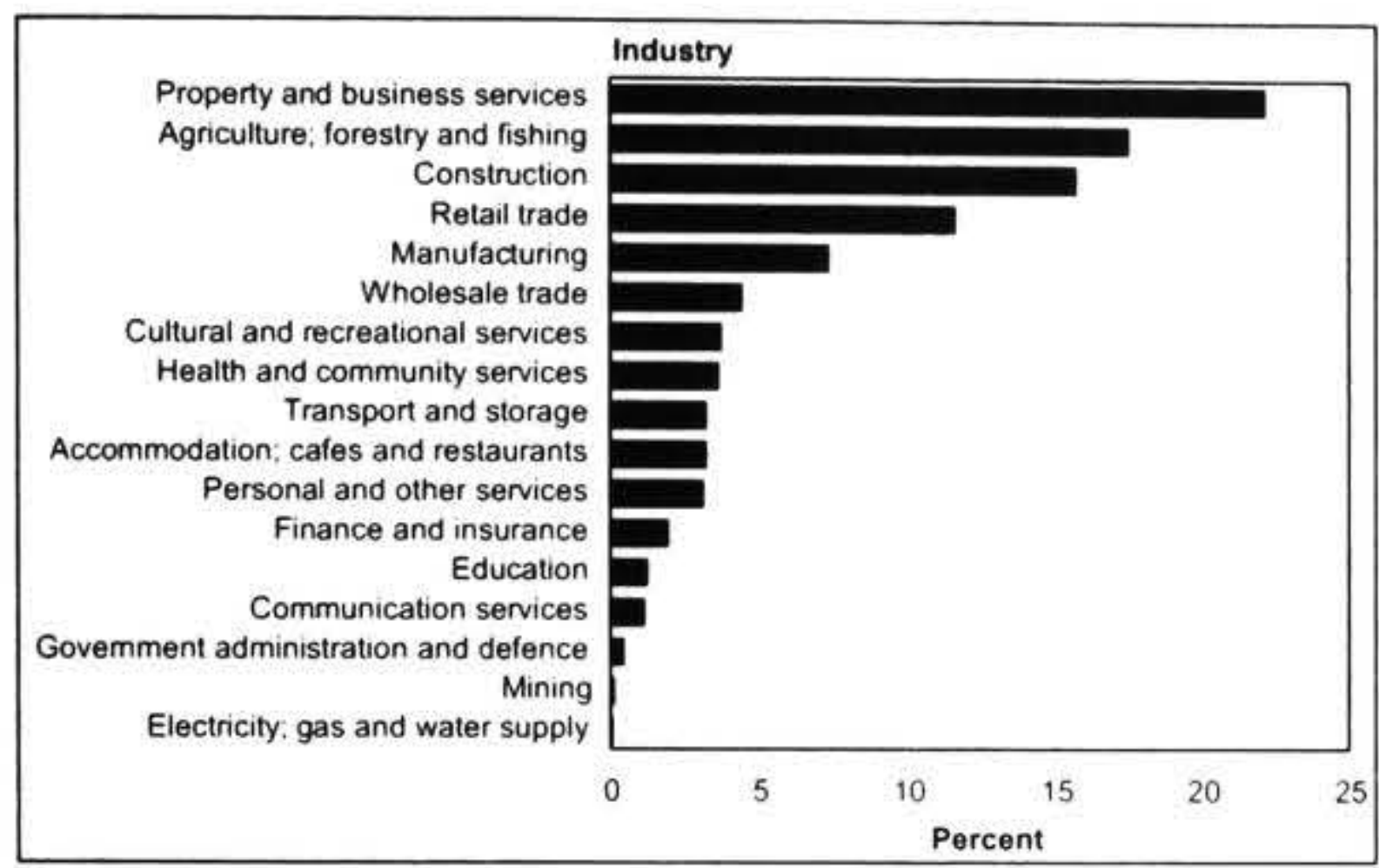

There were 377,670 self-employed people (or persons whose main earnings source was self-employment) in the 2005 tax year. The number of self-employed persons as a percentage of total employment was 17.4 percent. The self-employment rate has been steadily declining since the 2000 tax year, when it was 19.9 percent. Major factors behind the decrease were the strong growth in the number of people whose main source of earnings is wages and salaries and falling numbers of self-employed persons in the agriculture, forestry and fishing industry (which had the largest proportion of self-employed persons across industry in 2000). Between 2000 and 2005 tax years, the number of wage and salary earners grew by 20.9 percent compared with growth of only 2.2 percent for selfemployed.

In 2005, self-employed people were more likely to be male, aged 35 years or more, and working in the agriculture, forestry and fishing; construction; or property and business services industries. The self-employment rate (or percentage of total employment) for males was 20.5 percent compared with 13.8 percent for females. Median annual earnings of self-employed people was $\$ 30,350,3.7$ percent higher than wage and salary earners.

Self-employment has contributed significantly to job growth. Almost half of all self-employed people employed at least one employee in the 2005 tax year, up from 45.6 percent in the 2000 tax year. This is because, over this period, the number of self-employed people with employees increased by 10.3 percent. The number of selfemployed people who employed between 6 and 19 employees over this period has steadily increased, while the number of self-employed persons without employees has fallen. Many self-employed people develop their businesses, make capital investments, and employ other workers. The growing New Zealand economy in recent years has provided the impetus for many self-employed persons to become employers, and existing employers to hire more people.

\section{Earnings Transitions}

The longitudinal nature of LEED allows the comparison of people's earnings (both from wages and salaries, and self-employment) between two periods of time. The following analysis presents annual earnings as deciles to allow comparison of people's earnings over a five-year period. Deciles divide the population into 10 groups after ranking people according to the amount of annual earnings they received.

Figure 2 shows the percentage of males and females in each annual earnings decile in the 2005 tax year. A large percentage of part-time workers are female and this helps to explain why females are more likely than males to be in deciles 1 to 5 (less than \$26,540). Deciles 6 to 10 contain a larger percentage of males. The top decile (more than $\$ 63,820$ ) comprises 75.4 percent males and 24.6 percent females.

Figure 2: Annual earnings decile by sex, year ended March 2005.

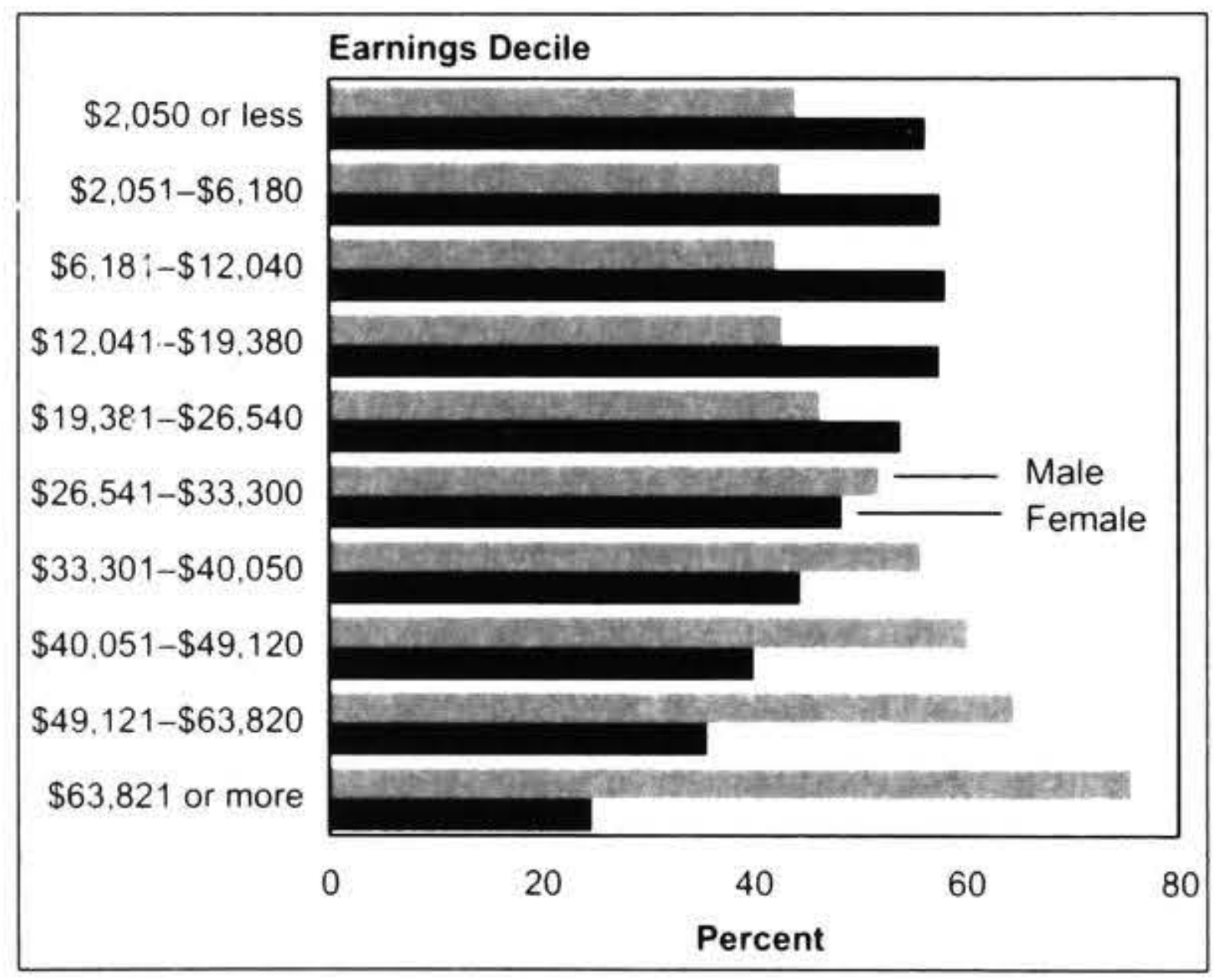

Nearly 1.7 million people received earnings in both 2000 and 2005. Of these, 45.0 percent moved to a higher earnings decile in 2005 (ie improved their rank in terms of earnings), 27.4 percent stayed in the same decile and 27.6 percent moved to a lower decile. While these percentages are similar for males and females, Figure 3 shows that males and females have different patterns by age.

Overall, figure 3 shows that the likelihood of someone moving to a higher decile (or increasing their earnings rank within the population) between 2000 and 2005 decreases with age. There could be a number of reasons for this: 
- The increase in earnings workers receive for gaining work experience is higher for less experienced workers. From then on, the increase in earnings is less.

- Those aged 20 to 29 years may have increased the hours worked from five years previously (eg by moving to full-time work post-study), causing a large increase in their earnings.

- Older workers may have reduced their hours of work since 2000 .

Females aged 20 to 34 years are less likely to have moved to a higher decile since 2000 than males, whereas females aged 35 to 54 years are more likely to have moved to a higher decile. This may reflect the impact of childbirth on female participation in the workforce:

- Females in the 20 to 34 age group may be more likely to be working fewer hours than in 2000 due to childcare responsibilities, and are therefore less likely to have moved to higher deciles than males.

- Females in the 35 to 54 year age group may be more likely to work more hours than they did in 2000 due to reduced child-care responsibilities. They are therefore more likely to have moved to higher deciles than males whose hours remained relatively constant. If women have also been out of employment for a number of years they may also experience large increases in earnings during their first years back in the workforce.

\section{Multiple Job Holding}

In the 2005 tax year, a quarterly average of 5.0 percent $(79,976)$ of workers (excluding self-employed), had two or more jobs. Of all workers, 4.7 percent had two jobs and just 0.3 percent had three or more.

Women were the majority of multiple job holders, 65.9 percent of the total in the 2005 tax year. Females made up 47.8 percent of workers with one job, but 65.4 percent of those with two jobs and 73.0 percent of those with three jobs or more. Across all age groups, female workers were more likely to hold multiple jobs than male workers.

Figure 4 shows that the distribution of workers holding multiple jobs across different age groups within each sex is distinct. A higher proportion of males aged 15 to 34 years held multiple jobs and again when aged 60 and over, perhaps reflecting student and retirement jobs. Women holding multiple jobs were more likely to be aged 35 to 64 years. This may be due to balancing employment with family demands.

Overall, median monthly earnings decreased with multiple job holding in the 2005 tax year. Median earnings for workers holding multiple jobs $(\$ 2,278)$ were less than those for workers with one job $(\$ 2,718)$ and earnings for workers with three or more jobs $(\$ 2,175)$ were less than workers with two jobs $(\$ 2,283)$. Earnings for females were lower than that of males regardless of the number of jobs held.

Figure 3: Proportion of employed moving to higher earnings deciles by sex and age group, year ended March 2000-2005 ${ }^{(1)}$.

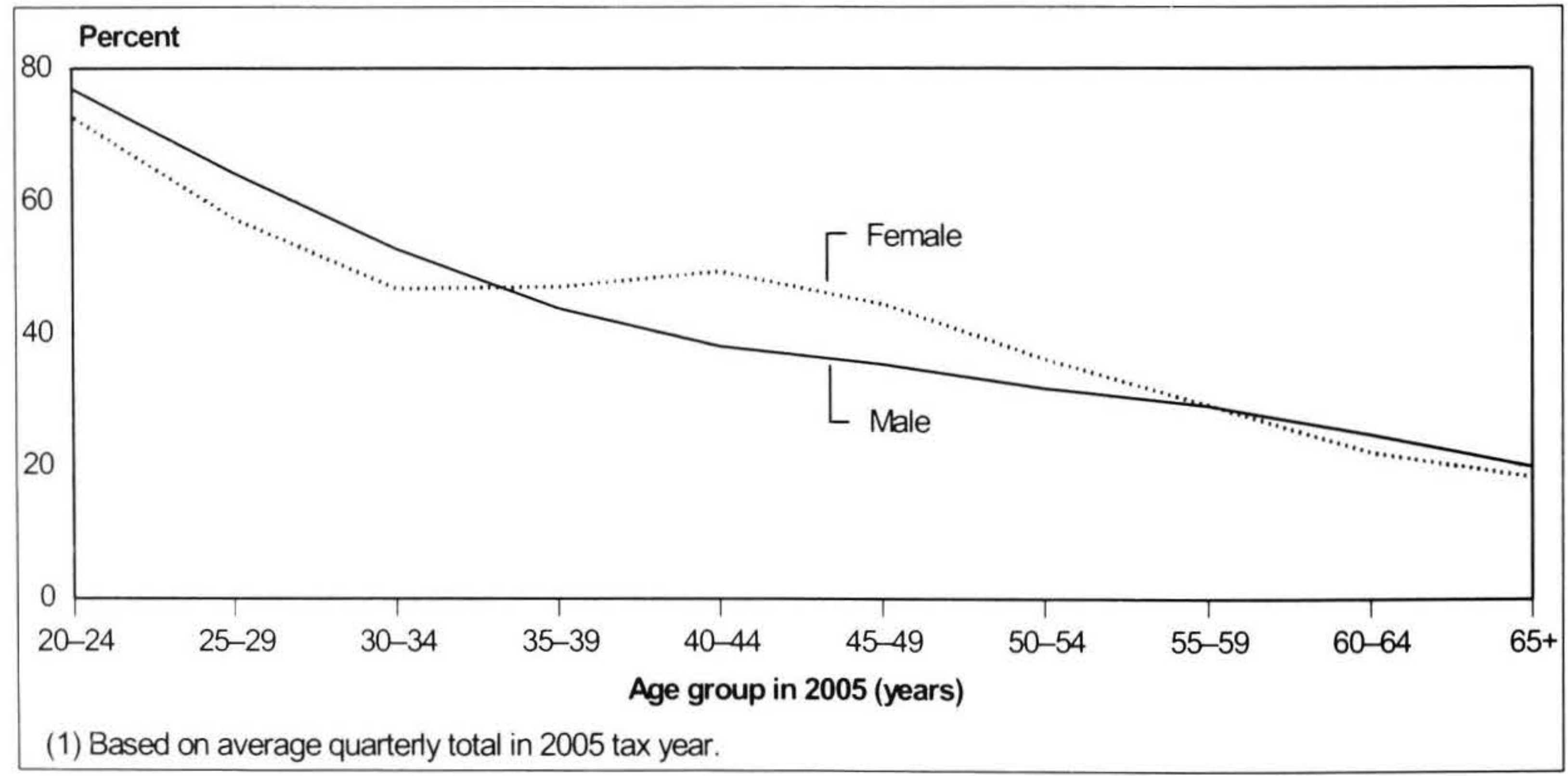


Figure 4: Distribution of multiple job holders by sex and age group, year ended March $2005^{(1)}$.

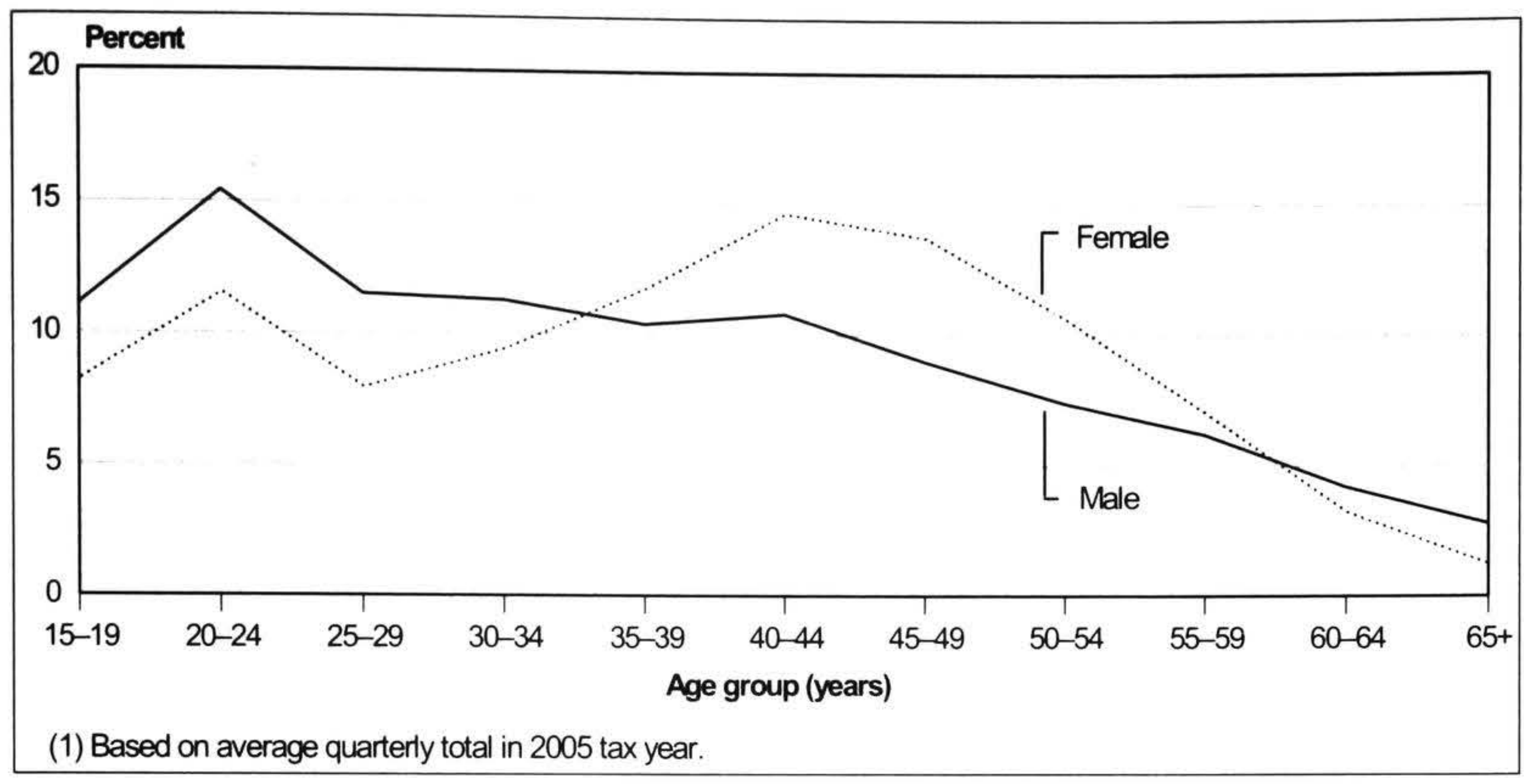

In the March 2005 quarter, the highest percentage of workers holding multiple jobs ( 16.0 percent) worked in the health and community services industry. In that industry, median monthly earnings of $\$ 2,340$ were above the median for all multiple job holders $(\$ 2,240)$. In contrast, the lowest percentage of multiple job holders worked in the mining $(0.1$ percent $)$; and electricity, gas and water supply industries $(0.2$ percent $)$, but these industries had the third-highest and highest earnings of $\$ 3,050$ and $\$ 4,220$, respectively.

A large proportion (73.8 percent) of multiple job holders worked in a different industry to that of their primary job. Property and business services was the most popular industry for secondary jobs for multiple job holders.

\section{Future Research}

Statistics NZ will continue to develop the measures produced from LEED. Comments on existing measures or suggestions for new measures are welcome. Please send them through to leed@stats.govt.nz

Note that access to LEED unit record data is restricted to Statistics New Zealand employees.

\section{Notes}

$1 \quad$ Privacy, security and confidentiality of personal details are critical to people who fill in statistical forms and provide information to the government as well as Statistics NZ. The Statistics Act 1975 protects this information. Access to data and personal details is strictly controlled and no individuals or businesses can be identified from the data Statistics NZ releases. LEED is used only for statistical purposes. The data is not available for operational or administrative purposes. In keeping with this policy, Inland Revenue provides data to Statistics NZ but Statistics NZ does not provide unit record data back to Inland Revenue. Any amendments made by Statistics NZ to the Inland Revenue data during processing are for statistical purposes and are not fed back to Inland Revenue.

\section{Authors}

Rodney Jer

Statistical Analyst

Work, Knowledge and Skills

Statistics New Zealand

P.O. Box 2922

Wellington

Rodney.Jer@stats.govt.nz

lan McGregor

Subject Matter Project Manager, LEED

Work, Knowledge and Skills

Statistics New Zealand

P.O. Box 2922

Wellington

Ian.Mcgregor@stats.govt.nz

Tas Papadopoulos

Statistical Analyst

Work, Knowledge and Skills

Statistics New Zealand

P.O. Box 2922

Wellington

Tas.Papadopoulos@stats.govt.nz 